\title{
The 7 Habits of Highly Effective People
}

\author{
Article Review by Rubina Jabeen \\ Nursing, Texila American University, Pakistan \\ Email:- rubinajabeen302@texilaconnect.com
}

\section{Source literature}

Part 2, Habit 2 (Begin with the end in mind), pages 96- 103 of the book "The 7 Habits of Highly Effective People" by Stephen R Covey, paperback edition published by Simon \& Schuster UK Ltd, Africa House 64-78 Kingsway London WC2B 6AH, 1992 and reissued in 1999 by A Viacom Company, and a copyright book under the Berne Convention.

\section{Introduction}

The excerpted literature is a fraction of Part 2, Habit 2 of the book "The 7 Habits of Highly Effective People". It discusses about the particular sense and explanation or rationalization of the meaning of Habit 2. To lead the readers into better position of understanding and broader perception of what it means to "Begin with the end in mind", the author establishes the clarity, definitions, and bases of common understanding between the reader and the author.

For an idea to be properly understood and digested by the readers, it is imperative for the author to provide a foundation of the facts, principles and definitions for the important matters being discussed about Habit 2 and its essence and significant connection to every contextual principle being considered and explained in the book.

The excerpt thus, elucidates the principles and bases on which habit 2 are based and founded upon. These explanations and bases help the readers to accurately understand the views and paradigms that the author is trying to convey to them. The extract explains that habit 2 is based on the principles of personal leadership and on the principle that "All things are created twice", however, not all first creations are consciously designed by a person himself. The author illustrates that if we do not generate our self-awareness, we will always reactively live by the influence of other people, environment and pressures of circumstances. This influence was termed by the author as scripts handed to us in our early years.

\section{Review of literature}

Habit 2 of the 7 Habits of highly effective people postulates that one way to be highly effective is to begin with the end mind. It means that you have to set your paradigm and goals and make a clear picture of how things should be at the end of your life. The goals you laid down will set the frame of reference and criteria of everything that you do in life and channel all your efforts to reach the goals. It means having a lucid thoughts and perception of objectives and end goals. You have to clearly define where you are going and recognize where you are now so that every stride will lead you to the right direction. Such principles have a valid application for people in walks of life. Without these principles, people stand prey and get lock in a very busy life without really being effective.

People strive so hard to get higher echelon only to discover that stairs they are climbing is tilted towards the wrong direction. Our extremely busy lives has plunged us into ineffectiveness that subsequently led us to attain meaningless triumphs that have cost us so many things that we later recognize to be more important to us. Our very busy struggle to climb the echelon leading to the wrong direction has obscured our vision, and only when these more important things in life were gone that we become aware that these were the ones that really matter to us.

"Begin with the end in mind" is based on the principle that all things are created twice (p. 99, para. 2). The first creation is the mental creation (plans, outline, design, raw details), and the second creation is the actual physical creation. Before we do things, before we make or 
construct anything and before we start anything, activity, project, and undertaking, we first plan and create a detailed mental visualization of procedures, system, organization, outcome, regulations and necessities. It means that before putting things into actual reality, we first mentally visualize all the details and necessities. Not all first creations, however, are consciously created by us. In considerable part and length of our lives, especially in the early years of our lives, we subconsciously and reactively live according to the influence of peers, elders, family, environment and circumstances. These influences were passed on to us as part of culture, customs, upbringing and ways of living and were termed as scripts. Unless we develop our own personal conscious capacity and self -awareness, we will not be able to clearly define and make our own personal "first creation".

In other words, "Begin with the end in mind" is also based on personal leadership. Which means that leadership is the mental creation (the first creation) and management is the physical creation (the second creation). To have a clearer distinction between leadership and management and as expounded by the author, try to visualize a group of manufacturers (leaders and problem solvers) clearing their way through a forest and the managers (procedure and policy makers) follow them to fix and sharpen all the equipment required to clear the way. The leader is person who goes up the highest tree and analyzes the whole scenario, and shouts that we are in the wrong forest. We are always busy clearing the underbrush without realizing that we are in the wrong forest. According to Peter Drucker and Warren Bennis, "Management is doing things right; leadership is doing the right things". Management is the competence in going higher in the echelon, and leadership ensures that the echelon stair is leaning towards the right direction.

\section{Article summary}

This article explicates Habit-2 ("Begin with the end in mind") of "The 7 habits of highly effective people". It means that in everything we do, we should start with a clear picture of our future or the end goal of our lives. We have to begin with our objectives and we have to recognize where we are today and where we presently stand to be able to find the best means and ways toward our end, our goal. Such end or goal will guide us to integrate and consolidate all our efforts, behavior, and visions towards that goal. Since it is very easy for us to be trapped in a very busy atmosphere of our lives, the end in mind will set the parameters to which everything we do will be referred and everything else will be scrutinized according to the context of such end or goal. Subsequently, this will ensure that as we struggle to go higher in the social echelon, the stair we are climbing is not leaning towards the wrong medium.

"Begin with the end in mind" is based on the principle that everything goes through two creations, the mental creation and the actual creation. All that we do and make are first visualized and planned with details before we actually execute and make them, but not all first creations are consciously created by us. Our own personal first creation is unconsciously influenced by our culture, customs, family, peers, training and environment, and unless we develop our personal awareness and realize that we should unshackle ourselves from this influence and be independent, we will not be able to make, manage and lead our own first creation.

That simply means that "Begin with the end in mind" is also based on the principle of personal leadership and that leadership is the mental creation and management is the second creation. Leadership will ensure that we are in the right direction and medium, and management will ensure that we have the appropriate requirements and equipment as we progress toward the end we have in mind.

\section{Article structure}

To illustrate how this article has been organized, the article structure is hereby provided. This will guide the reader on the format and arrangement of discussions and presentation of facts. At the outset are the facts regarding the source literature that will attest to the veracity 
and real existence of the academic material on which this article was based. This segment declares the details of the author, publisher, publication date, book etc. from which the source literature was extracted.

Immediately follows, is the introduction that purposely serves as an abstract and subsequently establishes the background of the source literature and this article. This particularly provides the readers with the bird's eye view of this article and the source literature, acquaints the readers about the topics, and guides the readers on what to expect in the succeeding discussions.

Follows thereafter is the review of literature. In line with the views of the author, this section fleshes out, re-evaluates and show the relationships of the most important points, ideas, principles, details and arguments of the source material This is the main discussion of the whole article that presents the re-examination of the concepts, facts, essence and the whole thought of the material.

After the review, comes the summary. It is the short version of the whole material itself. The summary pulls together all the major points. This section is the objective, condensed and concise restatement of author's main ideas including few opinions of the literature reviewer which are analogous to the author's views.

The last part of the article is the critique which is the objective evaluation of the aptitude and credentials of the author and the accuracy, currency, relevance and objectivity of the contents of the source material.

\section{Article critique}

\section{Authority}

Over his lifetime, Stephen inspired millions with the power of universal principles. As he travelled the globe many times over, his message was a simple one: for true success and meaning in life, we must be principle-centered in all areas of life. A teacher at heart, he often taught: "there are three constants in life: change, choice and principles."

From the oval office, the board room, community halls and to the school house and family room, Stephen taught the mindset, skill set and toolset found in the 7 habits of highly effective people, his seminal work. His legacy is woven in the 7 habits, and, just as these habits are universal and timeless, so is Stephen r. Covey, who is admired around the world for his simple, yet powerful, universal, timeless teachings.

Recognized as one of Time magazine's 25 most influential Americans, Stephen R. Covey was one of the world's foremost leadership authorities, organizational experts, and thought leaders.

Covey was the author of acclaimed books, including the international best seller, The 7 Habits of Highly Effective People, which has sold more than 25 million copies in 40 languages throughout the world. Other best sellers authored by Covey include First Things First, Principle-Centered Leadership, The 7 Habits of Highly Effective Families, and the 8th Habit: From Effectiveness to Greatness.

Recently released books authored by Covey include Everyday Greatness: Inspiration for a Meaningful Life (2006), The Leader in Me: How Schools and Parents Around the World Are Inspiring Greatness, One Child at a Time (2008), Predictable Results in Unpredictable Times (2009), Great Work, Great Career (2009), and The 3rd Alternative: Solving Life's Most Difficult Problems (2011).

Millions of people and thousands of clients throughout the world have personally experienced Covey's approach and commitment to teaching universal principles. His approach has been enormously empowering and it transcends differences of every kind-political, philosophical, religious, socio-economic, generational, gender, lifestyle, etc.

Over the years, clients from around the world - including from India, Japan, Korea, Africa, Israel, Saudi Arabia, Indonesia, and beyond-have commented to Stephen Covey that The 7 Habits intimately relate to their culture, country, organization, and family. He responded, "You recognize these principles because they are common to every society that prospers and 
endures." These universal, timeless principles have stood the test of time with millions of people around the world and will continue to do so in the future.

Stephen Covey passed away on July 16, 2012, with his loving wife, children and their spouses, grandchildren and great-grandchildren present. His legacy to the world is PrincipleCentered Leadership and his many contributions will live on through the principles he loved, taught and espoused.

\section{Accuracy}

All the main points, argumentations, paradigms, principles and ideas in the source literature were properly, clearly, accurately and logically explained. The details were very clear and were very reasonably presented and elucidated. The supporting explanations, evidences, examples and illustrations of the highly academic ideas and psychological realities were exceptionally factual and are precisely happening in our real life setting. The terminologies and word choices and the methods by which they were expounded were very easy to comprehend. The main points and the supporting ideas were logically organized. Subsequently, this certainly ensured a very smooth flow of ideas and well thought-of concept of presentation of facts and consequently this again guaranteed the comprehensive digestion of the whole literature. The truthfulness and accuracy of the facts and explanations were all based on real life settings and actual psychology of human behaviour. The references and the cited materials that help support the main ideas were taken from the works of highly qualified scholars who are experts in their respective field of discipline.

\section{Currency}

Considering that the book from where the article was taken was first published in 1992, the article is fairly old but its value and application did not and will not change or will be outdated with the passage of time. The article exemplifies the psychological realities of our modern day to day busy life. The truths expounded by the source literature are actually happening in our lives. Everything that were discussed and logically explained are factual and are based on the real psychology of human tendencies, actuations, behaviour, mores, culture, customs and traditions. In fact, all discussions and elucidations are true and are applicable and inherent to all kinds of human race living in this planet. Every point and its explanations in the source literature are based on real life experiences and are excellently articulated beyond reasonable doubt and beyond question. The psychological principles and aura of the main ideas are valid in any level of human life and have a very legitimate application for people in all walks of life. On personal note, most if not all the points examined therein, are true and still exist in my personal life and mostly are parallel and congruent to my own personal experience.

\section{Relevance}

The contents of the source literature are coherently and legitimately relevant to its title. Every information, idea and principle conveyed in the contents of the article explains and supports the main idea of Habit-2. The quoted materials and references were very relevant to the to the title and to the main ideas that were develop to clearly explain the meaning of "Begin with the end mind" and explicate the principles, realities and intrinsic psychological propensity on which the Habit 2 was based and instituted. The cited materials and references combined with the expertise and personal and real life experience of the author, explicitly articulated the relevance of the content to its title and further provided broader and straightforward understanding to the readers. The logical arrangements of ideas and detailed discussions, the coherence of sentences and paragraphs and the smooth transitions naturally verbalized their concrete significance and relevance to the title. Consequently, such relevance certainly facilitated an easy flow of comprehensive, conceptual and contextual absorption of the gist and essentials of the article. 


\section{Objectivity}

All the information contained and detailed in the source literature were gathered, organized and developed objectively based on facts and not on the subjective opinion of the author. Considering the fact that the cited materials and quotations from references that were used to support the major arguments and the essence of the article as a whole were taken from highly acclaimed books, scholarly writings and academic articles of authors who are excellent professionals and experts of their respective field of discipline, the contents of the article evolved from a highly objective collection of facts, real life experiences, academic endeavour, psychology of human nature and psychosocial realities. The contextual illustrations and examples that further explain the substance of the main ideas and the facts were objectively based on real life experiences and not on the emotional and sentimental opinion of the author. With reference to the credentials, track record, expertise and the scholarly writings of the author, it is very evident that the source literature was objectively developed, free from subjective judgement, personal biases, and opinionated partiality.

\section{References}

[1.] American Psychological Association. (2010). Manuscript structure and content. In Publication manual of the American Psychological Association (6th ed., pp.21-38). Washington, DC: American Psychological Association. (Education Library - Reference BF76.7 .A51 2010)

[2.] Bill Gordon: "A Closer Look at Stephen Covey and His 7 Habits" Apologetics Index. Retrieved December 23, 2007

[3.] Gandel, Stephen (August 9, 2011). Books". Time. Retrieved January 4, 2011.

[4.] Harper, Lena M. (Summer 2012). "The Highly Effective Person". Marriott Alumni Magazine (Brigham Young University). Retrieved August 11, 2012. Covey, S. R. (1989). Organizing change: Upward Spiral. Free Press.

[5.] English, L (2004). "The 7 Habits of Highly Effective Information Professionals, Part 7" (pdf). DM Review. September/October '04: 60-61. See for instance the chapter in Carolyn Simpson's High Performance through Negotiation.

[6.] Covey, S (2004). The Power of Character. Unlimited Publishing. p. 103.

[7.] Krayer, Karl J.; Lee, William Thomas (2003). Organizing change: an inclusive, systemic approach to maintain productivity and achieve results. San Diego: Pfeiffer. p. 238. 